\title{
El libro de Artista como recurso didáctico innovador y su potencial terapéutico
}

\author{
The Artist's book as an innovative teaching resource and its therapeutic \\ potencial
}

\author{
Alejandra Escribano \\ Universidad Nacional de Córdoba (Argentina) \\ argaodila@gmail.com
}

\author{
Recibido 11/08/2020 Revisado 10/11/2020 \\ Aceptado 17/11/2020 Publicado 30/11/2020
}

\section{Resumen:}

El libro de artista es un medio de expresión con parámetros totalmente distintos a los que conocemos tradicionalmente, como la pintura, la escultura o las obras literarias tradicionales. De esta diferenciación nace necesariamente un género artístico nuevo e independiente, que es fundamentalmente interdisciplinario y que posibilita cruces entre distintos campos del arte, el diseño y la artesanía se unen para desarrollar una idea. Se toma conciencia del libro como una entidad artística propia e independiente dentro del arte contemporáneo.

Este trabajo surge como una necesidad de aclarar conceptos sobre las fronteras que definen este género y de compartir las observaciones, impresiones y proyecciones basadas en la experiencia realizada a través de talleres dictados sobre el tema. Pretende atender a su posibilidad multidisciplinar en la construcción del lenguaje y la expresión y rescatar sus cualidades como un óptimo recurso didáctico innovador para el área educativa así como también un excelente medio para expresar cuestiones inconscientes o elaborar problemas emocionales.

$\mathrm{Al}$ no estar estratificado dentro de las normas, regulaciones y desregulaciones que sufren otras disciplinas, este género goza de cierta liviandad, la prioridad está en la expresión, y las posibilidades de ejecución para materializarla son múltiples. Existen libros sonoros, otros que representan escenarios teatrales, formas lúdicas que necesitan precisión matemática o geométrica para su ejecución, etc. Esta apertura a la diversidad posibilita el trabajo multidisciplinar integrando diferentes áreas del conocimiento: música, teatro, literatura, plástica, informática, matemáticas y otras.

En el trabajo con niños, de 8 a 12 años, estos incluyeron y aprovecharon de forma natural los recursos plásticos y literarios, narrando historias que expresaban sus fantasías, miedos y deseos. Los adolescentes pudieron plasmar con libertad y sin inhibiciones sus ideas, emociones y sentimientos, en creaciones personales y colectivas. En los talleres para adultos se observó la tendencia a crear libros de confesiones íntimas o "ritualizar" experiencias pasadas a través de la creación. En todos los grupos se destacó la camaradería y la valoración positiva de la obra propia y ajena.

\section{Sugerencias para citar este artículo,}

Escribano, Alejandra (2020). El libro de Artista como recurso didáctico innovador y su potencial terapéutico. Tercio Creciente (Monográfico extraordinario III), págs. 137-166, https://dx.doi.org/10.17561/rtc.extra3.5705

ESCRIBANO, ALEJANDRA (2020) El libro de Artista como recurso didáctico innovador y su potencial terapéutico. Tercio Creciente (Monográfico extraordinario III), noviembre 2020, pp. 137-166, https://dx.doi.org/10.17561/rtc.extra3.5705 
Abstract:

The artist's book is a means of expression with parameters totally different from those we traditionally know, such as painting, sculpture or traditional literary works. From this differentiation, a new and independent artistic genre is born necessarily, which is fundamentally interdisciplinary and which allows crossings between different fields of art, design and crafts come together to develop an idea. The book is made aware of as its own independent artistic entity within contemporary art.

This work arises as a need to clarify concepts about the borders that define this genre and to share observations, impressions and projections based on the experience carried out through workshops on the subject. It aims to attend to its multidisciplinary possibility in the construction of language and expression and rescue its qualities as an optimal innovative didactic resource for the educational area as well as an excellent means to express unconscious questions or elaborate emotional problems.

As it is not stratified within the norms, regulations and deregulations that other disciplines suffer, this genre enjoys a certain lightness, the priority is in the expression, and the possibilities of execution to materialize it are multiple. There are sound books, others that represent theatrical scenarios, playful forms that need mathematical or geometric precision for their execution, etc. This openness to diversity enables multidisciplinary work integrating different areas of knowledge: music, theater, literature, art, computing, mathematics and others.

In working with children, ages 8 to 12 , they included and made the most of plastic and literary resources in a natural way, telling stories that expressed their fantasies, fears and desires. The adolescents were able to express their ideas, emotions and feelings freely and without inhibitions in personal and collective creations. In workshops for adults, a tendency was observed to create books of intimate confessions or to "ritualize" past experiences through creation. In all the groups, the camaraderie and the positive evaluation of their own work and that of others stood out.

Palabras Clave: Libro de Artista, multidisciplina, recurso didáctico, arteterapia

Key words: Artist's book, multidiscipline, didactic resource, art-therapy

Sugerencias para citar este artículo,

Escribano, Alejandra (2020). El libro de Artista como recurso didáctico innovador y su potencial terapéutico. Tercio Creciente (Monográfico extraordinario III), págs. 137-166, https://dx.doi.org/10.17561/rtc.extra3.5705

ESCRIBANO, ALEJANDRA (2020) El libro de Artista como recurso didáctico innovador y su potencial terapéutico. Tercio Creciente (Monográfico extraordinario III), noviembre 2020, pp. 137-166,

https://dx.doi.org/10.17561/rtc.extra3.5705 


\section{Introducción}

El Libro de Artista es una manera de "hacer obra", relativamente nueva si tomamos como referencia a las disciplinas tradicionales; aún hoy existe la discusión sobre si es un género en sí mismo o si puede ser incluido dentro de otros. Este tipo de subordinación es propio de la dificultad de aceptar lo nuevo, que nace pero todavía no hay certeza, confianza, ni conocimiento que nos dé la seguridad suficiente para dejarlo independizarse. También deviene de su estrecha relación con el arte gráfico y la desvalorización histórica que este ha sufrido.

Origen

Si buscamos la definición de la palabra libro en el diccionario veremos que dice: reunión de muchas hojas de papel, que se han cocido o encuadernado juntas con cubierta de papel, cartón pergamino u otra piel y que forman un volumen. Pero también el libro es un continente de textos, desde un punto de vista formal y textual. El libro tradicional, dada su unidad literaria y su monotonía visual nos propone unos valores tranquilizadores y unitarios, desatiende el equilibrio, la armonía, las proporciones, la perspectiva y presta solamente atención a las leyes secuenciales del lenguaje, utilizando el alfabeto sin buscar nuevas relaciones con él.

Los libros de textos son unívocos, no intervienen más elementos que los puramente basados y fundamentados en la linealidad del clásico discurso. Estos libros y la información verbal que nos transmiten nos llevan a través del conocimiento a cambios de opinión y nuevas actitudes en el desarrollo de nuestro acontecer diario, el libro nos transforma, nos aconseja, nos enseña, nos abre a nuevas visiones, se convierte en nuestro cómplice y transforma nuestra vida.

Al margen de los contenidos, un libro es un objeto con un peso y unas medidas que nos dan un volumen en el espacio, con su propia realidad exterior y en su parte matérica y objetual también nos comunica una serie de sensaciones perceptuales, cuyo mensaje es "leído" desde los sentidos y no desde la racionalidad de la palabra escrita. 
Desde la Prehistoria hasta nuestros días, encontramos infinidad de obras, de todas las épocas y culturas que, aunque creadas con muy diferentes fines son precursoras del concepto actual de los libros de artista desde los huesos tallados, tablillas babilónicas, papiros egipcios, libros de oración tibetanos hasta los libros de la cultura cristiana. En casi todas las culturas encontramos relatos en forma de imágenes debido a la carencia de alfabetización, pero con el uso de la palabra escrita este modo de transmisión de conocimiento pasó a tener un papel secundario y a veces nulo en cuanto a narración de una historia y solo se conservó en los libros infantiles destinados a público-lector no alfabetizado.

Los artistas plásticos han elaborado libros desde hace dos mil años, esta tradición que incluye a Leonardo Da Vinci, Alberto Durero y William Blake entre otros.

Entre los precursores inmediatos de estos libros se encuentran: Los poetas Mallarmé y Apollinaire, los futuristas italianos, los dadaístas y los constructivistas rusos, todos ellos vinculados a la ruptura del texto y de la página tradicional con un mayor interés por el valor visual y espacial de la página. También Marcel Duchamp, asociado al movimiento Dada y por su obra "La caja verde". El op-art, el happenig, el arte cinético, el arte póvera, el arte conceptual y el grupo Fluxus, son antecedentes del género.

\section{Evolución y desarrollo}

El Libro de Artista se desarrolla conceptualmente dentro de los movimientos de vanguardia de los años '60 y principalmente desde dos corrientes: la Neodadaísta, cuando en 1961- Dieter Rot, arma un libro con comics y periódicos y surge el libro como proliferación multiforme y la Conceptual, con Edward Ruscha y sus 26 fotografías en blanco y negro, de 26 estaciones de gasolina sin edición, ni firmado, ni limitado. Defiendiendo el principio minimal del libro como secuencia de imágenes y sin pretensión estética.

En los '80 proliferan los múltiples como reacción a un arte elitista sin perder el concepto de obra original. El artista se dirige a un público más numeroso valiéndose de los medios de la tecnología actual. El valor no está en la naturaleza del material o de la técnica sino en la "originalidad del proyecto" que lo anima. Hay una desvalorización de lo bello en beneficio del contenido de significación. 
El libro aborda una escritura que ya no es solo literaria, es plástica. Nuevos soportes, formatos y materiales y un interés diferente por el soporte libro. Se comienza a utilizar este medio, tradicional vehículo de textos literarios o teóricos, para otro uso: el de la experimentación plástica, iniciándose la era del libro de artista, como medio autónomo de expresión, al margen de la tradición libresca o del arte convencional.

Se toma conciencia del libro como una entidad artística propia, creándose un nuevo género independiente, un género del arte contemporáneo.

Los libros de artista conjugan, el libro común, soporte tradicional de la expresión literaria, y las obras plásticas convencionales (grabado, pintura, escultura). La aproximación a un lado o al otro de este espectro nos acercará a las distintas tipologías del libro de artista; a veces cercanas a lo textual o literario y otras totalmente pictóricas, o escultóricas. Algunas obras son juegos visuales o táctiles, otras son soportes para transmisión de ideas y manifiestos. Los artistas contemporáneos, cada vez más ceden al rigor intelectual y el ascetismo estético propios de los '60 y se dejan seducir por un registro plástico, lúdico y táctil. Esta emancipación se traduce en un número creciente de libros imágenes, con formatos novedosos y encuadernaciones elaboradas, alejándose así del libro para hojear.

Es indudable que un pensamiento solamente puede manifestarse a través de un lenguaje el cual puede ser verbal o de signos. El lenguaje verbal es un discurso organizado sobre la base de signos unívocos con significación preestablecida, es un lenguaje concreto como sus conceptos El lenguaje de signos y símbolos, en cambio, es un discurso ambiguo, de significado vago y cambiante, es abstracto y su intencionalidad es la de sugerir, navegando sobre el curso de la sensibilidad, resumiendo y catalogando una serie de percepciones y sensaciones visuales.

El artista visual no rechaza el lenguaje verbal, sino que hace de él un material más para utilizar en su trabajo y lo emplea dándole nuevas significaciones, aludiendo a unas cosas por medio de otras. Trucos, juegos, rodeos del lenguaje son utilizados como alegorías y metásforas, transmutando la información puramente semántica del lenguaje en una información estética. 


\section{Relación artista-libro/público-lector}

Más que un arsenal de ideas los libros de artista son una experiencia consumada donde los artistas aplican todas sus cualidades para incitar al lector a forjar activamente la experiencia de la "lectura". Debe "capturar" al lector, a quien le corresponde estar abierto a nuevas posibilidades, prepararse para disfrutar, entender y consumir este tipo de obra.

El libro de artista es algo misterioso, personal y siempre táctil. Del mismo modo que la intimidad del libro seduce al artista para crear, el espectador entra en interacción con esa intimidad, que así se le vuelve accesible. El espectador aumenta el mensaje del objeto al aportar nuevas identidades a las viejas ideas, no sólo en su papel de consumidor de los conceptos plasmados por el artista en el libro, sino también enriqueciéndolos con su propia experiencia. Es una relación interactiva donde el espectador termina la obra al recrear y modificar las reacciones emocionales del artista, hay ocasiones en que el lector es a su vez un nuevo creador de la obra. Así llega a ser una forma de arte más asequible porque nos presenta una comunicación emocional potente, vívida y genuina.

Existen sensaciones que al intentar expresarlas nunca quedamos satisfechos con los resultados. Estas son las situaciones que el nuevo lenguaje ayuda a resolver. Los libros que este lenguaje plantea son realidades autónomas, autosuficientes y más internacionales que el tradicional libro escrito y muchos de estos no necesitan ser traducidos.

Un libro de texto, hace que nos involucremos de forma activa por medio de la mente, el libro de artista aporta otros modos perceptuales. Con su capacidad para expresar emociones fuertes, las artes gráficas han sido una herramienta útil para muchos artistas, sobre todo mujeres; que con el surgimiento y activismo de los primeros movimientos feministas se expresaban en la vía pública con fragmentos de recuerdos, frases o fotos. Este modo de expresión evolucionó en dirección hacia la intimidad como forma de arte y al sentimiento del "yo", generando una estrecha relación entre lo privado y lo público. Al saber que el libro solo requiere de un "lector" a la vez, el artista se siente menos abrumado por el proceso de convertir algo tan propio en un evento colectivo. El artista solo percibe un diálogo entre el creador y el espectador y usa como instrumentos el silencio y la intimidad. En la elección natural por temáticas profundamente personales y al utilizar símbolos y arquetipos pertenecientes al inconsciente colectivo, genera en el lector, estados de identificación y empatía. Se habla de un corazón roto, de la abuela, de los hijos que se fueron, de la infancia....de sentimientos o imágenes que todos hemos tenido de una u otra manera. 
El libro de artista, se torna así en un círculo de recuerdos, siempre sacados de la experiencia y de tipo autobiográfico.

Muchos artistas sienten que el libro es una galería que se toma en la mano, algo personal que constituye una experiencia única, "en ellos siempre hay imágenes de cosas sobre las cuales no teníamos imágenes". Con múltiples capas y estratos de ideas, un buen libro artístico siempre justifica nuestra atención e induce al lector a interactuar con la obra, ya sea en forma imaginativa o física. Los recursos que el libro de artista ofrece abarcan también, posibilidades educativas favoreciendo la interrelación entre las distintas áreas, presentándose como un recurso didáctico innovador para las escuela

\section{Ámbitos de circulación}

Desde 1970 los libros artísticos han llegado a ser estructuras y contextos para experimentos derivados del discurso de las artes visuales, en rápida evolución y gracias a ellos la gente puede poseer una obra de arte que es a la vez dinámica, experimental y de precio accesible. Al final de este milenio han vuelto a surgir tanto el fervor de la experimentación y el descubrimiento, como el fulgor de la reciprocidad artística y social entre los creadores de estos libros.

En los '60 los artistas querían salir de los circuitos elitistas de las galerías. Su actividad se inscribía deliberadamente en los circuitos paralelos que les aseguran medios de producción y difusión autónomos. Esta red a la vez restringida e internacional asocia estrechamente a los artistas - editores (que a veces son los mismos), coleccionistas, críticos, centros de distribución y de documentación alrededor de una preocupación común.

Han sido los propios creadores quienes, a base de presentaciones y muestras han formado un público incondicional y cada día más numeroso.

Actualmente existen algunas galerías y editores que se especializan en libros de artista, salones, bienales y trienales de arte gráfico han ido paulatinamente incorporando al género en sus convocatorias. La camaradería existente entre los autores de libros de artista, se ve reforzada cada vez más a través de la comunicación establecida mediante el uso de redes sociales. 


\section{Clasificación}

Las posibilidades tipológicas, formales, conceptuales y técnicas de los libros de artista son muy variadas; sus infinitas formas creativas hacen necesario aventurarse a un intento de clasificación, teniendo en cuenta que cualquier propuesta quedará siempre superada por su variedad y complejidad y que muchos libros podrán situarse en varios apartados simultáneamente.

Según algunos estudios sobre este género, la clasificación más primaria estaría dada por el número de ejemplares realizados de cada libro, tendríamos, : El libro de artista de ejemplar único y el libro de artista seriado.

\section{I) Libro de ejemplar único: un solo ejemplar firmado por el autor}

Esta categoría pude subdividirse en: Libro de artista original, Libro-montaje, Libro Objeto y Libro Intervenido.

\section{II) El Libro de artista seriado}

El libro de artista seriado (con un número de ejemplares que suele ir de cinco a mil ejemplares), está realizado en su mayor parte o en su totalidad por un artista plástico utilizando las más diversas técnicas de reproducción, desde la repetición manual a las técnicas tradicionales de grabado, el offset, la electrografía, impresos en computadoras y otros...pero siempre controladas por el propio artista.

Otra posibilidad es la edición del libro por una editorial especializada en libros de artista; para poder denominarlos así, la edición tendría que estar pensada, diseñada, realizadas sus planchas o prototipos por el artista, quedando la editorial encargada de poner los medios para su reproducción exacta, bajo la supervisión del propio artista. La tirada tendría que estar limitada y los ejemplares deberían estar firmados y numerados por el artista, lo mismo que una obra gráfica.

La confusión entre el Libro de artista y el libro de Bibliofília se aclararía si el libro de artista se realizara según lo anteriormente dicho, quedando la edición de Bibliofília totalmente a cargo del editor en cuanto a la decisión temática, formato, materiales y número de ejemplares. 


\section{III) Libro de artista original}

Manteniendo una estructura formal semejante a algunos de los soportes tradicionales literarios, el artista realiza una obra plástica única por cualquier procedimiento.

\section{IV) Libro-montaje}

Las obras que situadas en un espacio, actúan sobre ese espacio o que sus dimensiones tridimensionales sobrepasan el formato tradicional del libro, condicionando al espectador en su relación con el entorno.

\section{V) El Libro Objeto}

El libro objeto, fué bautizado así por el editor Georges Hugnet en 1930, tiene su origen en los libros ilustrados. En la actualidad se utilizan diversos materiales: aluminio, plásticos, cajas esculturas, maderas, etc. Luego se inspiran en las técnicas de collage del Pop Art, acumulaciones del nuevo realismo y materiales de recuperación del arte Póvera.

La obra se realiza con disposición tridimensional, contemplándose como una totalidad en su forma.

Los editores del sector libro dejan fuera de sus proyectos este tipo de publicaciones por ser de difícil ejecución, caros y minoritarios y salvo alguna pequeña editorial marginal, la mayoría son autoediciones, de corta tirada y técnicas artesanales.

\section{VI) El Libro Intervenido}

Partiendo de un libro de edición normalizada, el artista manipula este libro hasta convertirlo en una obra propia.

La modificación de libros "encontrados" hace aún más seductor el libro único. El artista altera libros impresos para crear con ellos retablos (pintando, perforando, remachando) y recipientes suprimiendo, solapando textos, pegando sobre las páginas, superponiendo tintas al texto original o cualquier otros posibles recursos. Produce una nueva obra a partir de otra que ya existía, la exploración de lo pasado en el presente crea un lienzo interesante para el artista. 
El artista infunde a los materiales su sentido íntimo, deja su marca deliberadamente, liga el libro tradicional a las distintas partes que serán los recipientes de lo trascendental actualizándolo y tendiendo así un canal entre lo viejo y lo nuevo.

Otras posibles clasificaciones de los Libros de Artista estarían dadas por su contenido, por el movimiento al que pertenecen, por el destino para el que están realizados, por su formato, por su temática, por su soporte, por sus técnicas o de otras múltiples maneras.

Así aparecen los llamados: Libros de viaje, conceptuales, minimalistas, móviles, combinatorios, xilográficos, constructivistas y otros.

\section{VII) Minimalistas}

Introducen la serie en el desarrollo temporal de la paginación, desarrollando estructuras elementales a lo largo del libro. Las posibilidades de utilización de líneas, figuras geométricas y colores.

\section{VIII) Conceptuales}

El concepto desplaza al objeto y se reduce a lo esencial: enunciados, propuestas, proyectos que se concretan en textos, listados, fotografías u otros. El libro de artista será su soporte ideal. En lugar de exposiciones, se realizan publicaciones.

\section{IX) Libros de escritura}

Algunos son facsímiles, otros experimentan con la escritura o la caligrafía al límite de lo legible, por lo que están cerca de la poesía concreta.

\section{X) De acumulación, colección o inventario}

Recopilación de imágenes, objetos o datos con algún nexo en común pero mostrados sin un orden concreto.

\section{XI) Libros de imágenes}

Tratan de contar una historia secuencialmente con sus imágenes manteniendo un hilo conductor narrativo. 
ISSN: 2340-9096

https://dx.doi.org/10.17561/rtc.extra3.5705

\section{XII) Libro sobre el libro: el libro común como objeto de reflexión.}

El propio libro como protagonista en primera persona.

\section{XIII) Libros táctiles}

No se parte de un libro ya editado sino que se crea. Diversos materiales proporcionan más posibilidades táctiles realzando lo matérico.

\section{XIV) Libros manuscritos / libros de viaje}

A modo de diarios o libros de viaje, suelen tener como soporte básico el papel.

\section{XV) Libros de soporte o pintados}

La narración plástica se realiza en las páginas consecutivas de estos libros.

\section{¿Qué es un Libro de Artista?}

La definición del diccionario Larousse de 1998, dice sobre el Libro de Artista:"Obra en forma de libro, enteramente concebido por el artista que no se limita a un trabajo de ilustración. (Bajo su forma más libre, el Libro de Artista se vuelve Libro-objeto)"

Las fronteras para definir qué es libro de artista y qué no lo es, parecen nebulosas y dan lugar a opiniones diversas, sin embargo existen datos y precisiones suficientes para poder discernir estas cuestiones.

Muchas veces se confunden obras de arte conceptual con libros de artista solo porque poseen un texto impreso sobre un volumen o catálogos tipográficos hechos por diseñadores, debido a la presentación, troquelado o uso del diseño tipográfico. Para poder discernir si una obra es o no un libro de artista se debe tener en cuenta si hay un relato, este no necesariamente debe ser textual, puede tratarse de un recorrido visual o táctil. Pero siempre es una narración que se vale de la representación y es posible percibir si la obra fue o no creada desde el concepto de libro.

No son libros de artista: Los libros ilustrados, o los libros en donde se presentan fotografías de obras de algún artista. Las obras expuestas como catálogos o ficheros en cajas, pero que no evocan nada más allá de lo expuesto. 
Si bien el libro de artista tiene antecedentes en la poesía visual, esta particularidad no es suficiente, pues parte de la idea de hacer poesía y carecería de las características antes mencionadas. Sin embargo hay poesía visual que posee un carácter lúdico narrativo, donde el espectador activamente pliega o rearma otra poesía y ha sido concebido como de libro de artista. Otra posibilidad cercana al género son las cajas colectivas, contenedores o Revistas ensambladas. Como tal obra colectiva, aunque tenga un argumento concreto, no se consideraría un libro de artista puro, si los artistas no forman un equipo o grupo consolidado. Al mismo tiempo existen publicaciones marginales, boletines de mail art y todo tipo de publicaciones de artistas plásticos que estarían en la órbita de los libros de artista, creando un mundo complejo pero de extraordinaria riqueza.

\section{Exposición}

Los libros de artista deben ser leídos en un contexto adecuado, este tipo de obra no puede ser expuesta de manera tradicional como en una exposición de pinturas por ejemplo; para ellos, es necesaria la creación de un espacio adecuado, un contexto a modo de instalación donde el lector pueda sentirse cómodo dentro de un marco que propicie la intimidad y permita una adecuada manipulación de la obra. El factor temporal que hace a una historia o a la narración de un libro, se traslada a la realidad de necesitar "tiempo" para poder disfrutarlo.

Aquí se plantea un nuevo problema a resolver: el espacio y dentro de este el Montaje.

En el caso de los mencionados talleres, se optó por unificar las diversas temáticas cubriendo con tela blanca cada uno de los rincones que habrían de contener la obra propiciando un espacio íntimo para que el lector-expectador, pueda disfrutar y manipular el libro tranquilamente. El público se acomodaba en una cama a leer los libros de sueños o ensueños; se sentaba en un sillón con escritorio antiguo para mirar los libros sobre historia Argentina e identidad, o se situaba entre mantas y maíces para apreciar relatos sobre culturas aborígenes.

Normalmente se ofrecen junto a los libros un par de guantes blancos para uso del público, evitando de esta manera el deterioro del libro por la reiterada manipulación de los espectadoreslectores. 


\section{Potencial terapéutico}

La condición de intimidad que el libro implica, provoca que el autor se sienta confiado al expresar sus ideas y emociones, abriendo así un portal de oportunidad para confesarse ante otro, tanto cuestiones reales como imaginarias o en ocaciones crear una trama mixta de biografía y fantasía. De este modo, la mascota real de un niño puede tornarse alada y transportarlo a otro mundo o ser su aliada para vencer una batalla fantástica en dónde el proptagonista (representación idealizada de sí mismo) es un super-héroe dispuesto a mejorar el mundo.

Al presentar la posibilidad de trabajar con collage, fotocopias o textos, el artista no se ve inhibido por su falta de destreza para realizar una imagen, razón por la que tampoco es necesario un conocimiento previo, es suficiente tener claro el concepto de la obra y la necesidad o deseo de transmitir esa idea fielmente. Esto explica por qué, es un género del arte contemporáneo, pues su virtud no se funda en la habilidad representativa sino en la idea que anima al proyecto y la capacidad de llevarlo a cabo. Esta circunstancia habilita a todo ser humano la posibilidad de crear.

Los jóvenes, suelen trabajar el collage, pegando trozos de papeles que ha ido guardando debido a la impronta emocional que dejó en ellos un suceso, trazos de significancia que ordenan un período emocional anterior, propiciando un cierre a modo de recapitulación creativa de su pasado, así una adolescente puede plasmar sus ilusiones amorosas cambiando los personajes, protegiendo su identidad en esta suerte de anonimato. En los dichos talleres los estudiantes construyeron libros objetos con formatos de cajas de juego, las cuales poseían una significación oculta, otros libros que narraban los mensajes recibidos durante el sueño o libros perfumados para exorcizar o atestiguar historias de amor. Las diversas situaciones que combinan relatos individuales verdaderos y autoprotección identitaria se amparan en la ambigüedad de las que podríamos llamar "confesiones inventadas", ya que es imposible determinar donde comienza o finaliza el relato de la historia personal y dónde el de la fantasía; muchas veces relatos reales y fantasías se entretejen, haciendo valer en la imaginación y materialidad de la obra, lo que se desea en la realidad; como un acto de psico magia y también de esperanza.

La ventajosa opción que implica poder unir lenguajes, textos e imágenes en la narración, pone en función los dos hemisferios cerebrales aumentando el caudal creativo para la ejecución de las obras permitiendo crear mediante la acción, encontrar recursos materiales que expresan y a la vez proponen nuevos sentidos.

Las características dadas en el plano conceptual se vuelven también de orden práctico y lo que ocurre a nivel individual se expresa en el grupo que habitualmente interactúa y colabora dando sugerencias para apoyar el trabajo de los otros, cabe destacar que dichos aportes siempre 
fueron bien recibidos. Alguien trae un objeto, dibujo u otro material encontrado para el libro de algún compañero. Aparecen los elementos justos $\mathrm{y}$, parafraseando a los alumnos: "como por arte de magia". Este tipo de "casualidades" siempre se presentaron siguiendo el flujo de la energía, que causaba encuentros asombrosos (fotos, un pequeño baúl, un texto). Es un trabajo integrador en dónde la confianza se torna el eje fundamental de la experiencia. Tal como se ha mencionado lo privado se hace público, el trabajo individual toma matices colectivos en cuanto a la actitud colaborativa, el intercambio conceptual y el propósito creativo. Los participantes se comunicaron con respeto mostrando apertura de sentimientos e ideas, libres y faltos de prejuicios. En un clima de relatos y confesiones se sintieron potenciados y manifestaron alegría $\mathrm{y}$ alivio al finalizar los talleres.

Al ser un género relativamente nuevo y no estar estratificado dentro de las normas, convenciones, regulaciones y desregulaciones que sufren otras disciplinas el libro de artista goza de cierta liviandad, la prioridad está en la expresión (que muchas veces abarca más allá de lo esperado) y también hay que contemplar que las posibilidades para la materialización de una idea son múltiples. Parecería que lo personal se diera al anonimato para dejar espacio a algo más esencial y profundamente humano, esta situación genera así una fuerte camaradería, complicidad y empatía dentro del grupo de autores donde se respira un clima marcadamente emocional.

Es importante mencionar que no hubo ningún participante que se avergonzara de su trabajo, por el contrario, se destacó la valoración positiva de la obra propia y ajena.

Los integrantes de los cursos y talleres manifestaron haber sentido algo terapéutico, liberador o ritual en la creación de su primer Libro de Artista.

\section{Un gran recurso didáctico}

Los recursos que el libro de artista ofrece abarcan también posibilidades educativas favoreciendo la interrelación entre las distintas áreas, presentándose como un recurso didáctico innovador, como diario o bitácora que pueda albergar libremente las ideas del diseñador o como formato en la presentación de Trabajos Finales.

Durante un encuentro Universidad-Escuela media, los alumnos trabajaro en un libro de gran formato $(1 \mathrm{~m} \times 70 \mathrm{~cm})$ divididos en grupos de $3 \mathrm{o} 4$ participantes por página, plasmando sus expectativas respecto a la educación superior, la sinceridad de lo expresado tanto en texto como en imágenes posibilitó un recurso extraordinario a los fines del proyecto. Los alumnos trabajaron en perfecta armonía, apoyándose y compartiendo ideas. También se establecieron comparaciones con el diseño empleado en la gráfica actual para presentar CD musicales, especialmente de bandas de rock y la opción de incluir el lenguaje del comic. Estos recursos 
favorecieron la identificación generacional y el entusiasmo de trabajar con un lenguaje afín, método del collage y la relación que el libro de artista establece con el comic, anima a los adolescentes a expresarse más libremente.

En cuanto a lo referente al trabajo en la escuela primaria y media, el Libro de artista ofrece múltiples alternativas para realizar trabajos que integren las distintas áreas de conocimiento: matemática, geografía, literatura, plástica, informática, música, historia y una amplia variedad de conocimientos pueden ser desarrollados y contenidos dentro del género.

Los adultos realizaron libros narrando la historia de la República Argentina con el formato de un documento de identidad de 50 x $70 \mathrm{~cm}$ o interviniendo libros de estudio sobre la historia del país. Otros, aprovechando la posibilidad táctil que el género ofrece, crearon libros para no videntes utilizando los códigos del sistema Morse generados a través de puntos de textura sobre papel. Entre los grupos de adultos se trabajaron temáticas diversas, tales como los culturas aborígenes, resignificaciones históricas a partir de libros de historia intervenidos, reconstrucciones autobiográficas, críticas sobre temáticas ecológicas, identitarias, sociales y políticas; relatos familiares sobre los hijos que partieron o historias de amor, narraciones de ficción y otras variantes entre la crítica y el deseo...los participantes más tímidos reconstruyeron biografías originales sobre algún escritor o artista al que admiraban profundamente.

En el marco de cátedras abiertas, en la Universidad Provincial de Córdoba he dictaron talleres en la Facultad de Educación y Salud y en la Facultad de Ate y Diseño, de estas experiencias resultaron libros educativos con temas como diversidad y cuestiones de género, además de libros de artista y libros objetos con objetivos pedagógicos, realizados por los estudiantes de la FES.

Realizamos un libro colectivo de 70 x $50 \mathrm{~cm}$, donde los alumnos construían las páginas grupalmente, este libro, luego de realizado, fue itinerante por las otras bibliotecas de la UPC, a fin de ser leído por los otros miembros de la comunidad educativa. El tema era "paz y convivencia en la diversidad", de allí surgieron interesantes reflexiones que quedaron plasmadas, además de vivir esta experiencia que según manifestaron fue enriquecedora y auténtica pues al trabajar más de uno por página necesariamente estamos conviviendo en paz, en la diversidad.

Siempre he pensado que el libro de artista es un recurso didáctico excepcional y espero a la vez que intento su práctica y difusión como tal, respecto a la FAD, una estudiante llevó la idea de trabajar un libro de artista colectivo a una biblioteca popular dónde es voluntaria junto con dos compañeras (una filósofa y psicóloga) para ser realizada por niños carenciados que acuden allí como refugio; los resultados fueron excelentes, los niños se expresaron, participaron y algo sanador ocurrió para bien, según me manifestó esta alumna. 
Los estudiantes de la FAD (Facultad de Arte y Diseño) UPC, también realizaron libros individuales y colectivos que reflejaban sus reflexiones sobre diversos temas, tanto personales como sociales; aquí aparecieron cuestiones de género, violencia y etiquetas sociales que fueron bien resueltos dentro de las distintas categorías que el género contempla.

Es importante destacar que los libros de artistas colectivos permiten la reflexión grupal contemplando la diversidad de miradas, esto es muy interesante a nivel tanto humano como pedagógico, ya que, durante la producción de la obra-libro las personas se enriquecen y aprenden a ligar ideas y sentimientos ajenos con el propio, se logra así una comunicación altamente positiva que enaltece las ventajas propias de la interacción.

También, al ser un libro colectivo los participantes se animan a exponerse pues se sienten contenidos en el semi-anonimato que ofrece la creación grupal, dónde todos somos uno y los estados anímicos se comparten pudiendo tomar más distancia de lo propio que toma otra dimensión en el conjunto.

La interacción colaborativa, la escucha y las devoluciones por parte del grupo completan el aprendizaje.

Como recurso didáctico, el libro de artista permite una expresión que se completa con el texto, reflexionar en la acción, esto es importante porque al trabajar con el collage, o utilizar como soporte un libro convencional transformándolo, aparece el azar en diálogo proponiendo lo impensado o previsto. Al ser una narración exige el desarrollo de la idea, por su versatilidad temática y constructiva como forma de arte en todas sus versiones (libro objeto, libro intervenido, libro digital, instalación y otros) posibilita el trabajo entre diferentes materias educativas y, (si hablamos de un libro colectivo) la elaboración de estas idea grupalmente.

Actualmente las universidades de diseño no incluyen al libro de artista por considerarlo de carácter artístico, sin embargo, estos libros mantienen cuestiones editoriales como el tiraje, la materialización de conceptos en tipografías e imágenes, así como formatos, soportes y tipos de impresión. Es importante que los libros de artista contemplen el diseño editorial ya que tienen sus antecedentes en el libro tradicional, su forma de leerse es similar, por lo que aplican numerosas reglas del diseño editorial basadas en el comportamiento del lector.

Es una realidad que en las expresiones de arte contemporáneo las disciplinas se cruzan y las fronteras se vuelven difusas, los diseñadores sienten que su trabajo tiene que ver con el arte y así es, el libro de artista resulta la perfecta convergencia entre ambas disciplinas ya que manejan las mismas herramientas visuales para la comunicación de mensajes específicos.

Los libros de artista contienen textos, dibujos, gráficos, fotografías y en todos los casos, obedecen a un diseño. 
ISSN: $2340-9096$

https://dx.doi.org/10.17561/rtc.extra3.5705

\section{Redes sociales}

El hiperlibro-arte es un libro-arte producido exclusivamente mediante estructuras tecnológicas digitales interactivas.

La versión digital del libro de artista es necesaria para una difusión adecuada a la migración digital que vivimos en este momento, de tal modo que se vuelve multimedia al incorporar animación basada en fotografías y una visualización completa similar a la de hojear un libro.

"El e-libro-arte es un libro-arte servido en un soporte electrónico que precisa para su visualización de una pantalla textual, una pantalla gráfica, y/o unos dispositivos de emisión de audio, video, etc.

El libro-arte en el contexto digital presenta dos clasificaciones: el e-libro-arte (libroarte electrónico) y el hiperlibro-arte

Se pueden distinguir e-libros-arte originalmente impresos que han sido digitalizados y ocasionalmente pueden imprimirse nuevamente y e-libros-arte digitales creados para poder ser impresos.

Los elementos específicos de la esencia del libro-arte son las particularidades y posibilidades de manipular la secuencia, el texto y la forma."

Hipertexto y escritura visual del hiperlibro-arte, Bibiana Crespo-Martín

En relación a Libros colectivos y Redes virtuales, debido al aislamiento preventivo obligatorio que algunos países hemos vivido por causa del covid19, el libro de artista proporcionó los recursos necesarios para una construcción colectiva, lanzando 2 convocatorias, desde en la Universidad Provincial de Córdoba: LOSOTRO y otra desde la Universidad nacional de Córdoba dentro del programa VENTANAS propuesto por la secretaría de extensión universitaria. Estas convocatorias aún permanecen abiertas, si bien ya podemos apreciar como parte de la experiencia algunos resultados en el valor de los trabajos enviados hasta el momento y el interés del público por participar.

La esencia de un libro de artista es ser objeto y concepto, la realización de un libro supone un marco de cooperación que desemboca en una creación determinada en relación a su contenido. 


\section{Referencias.}

Baudrillard, Jean: El Sistema de los Objetos, Siglo Veintiuno Editores, México, 1997.

Bozal, Valeriano. Historia de las Ideas Estéticas y de las Teorías Artísticas Contemporáneas.

Vol. I y II La balsa de la Medusa. Madrid 1996.

Chipp, H. Teorías del Arte Contemporáneo. Akal. 1995.

Daghero, Guillermo, "Tres Puntos Suspensivos sobre el Libro Objeto", publicado en Beta Test (revista electrónica), Córdoba, Mayo 2003.

Danto, Arthur. Después del Fin del Arte. Paidos. Madrid 1999.

Deleroix Moeglin “El Libro de Artista - El libro objeto - Edición Centro Pompidou 1990.

Deleuze Gilles y Félix Guattari: Rizoma, Pretextos, Valencia, 1980.

Ono Yoko: Pomelo, Ediciones de la Flor, Buenos Aires, 1970.

Pompidou, Georges /Esto no es un libro (tr,) Livres D'Artistes - Collection Semaphore, Centre BPI et Editions Herscher, París, 1985.

Reese Hourvitz Suzanne y Anne Stengel Raman, "Único en su género" Libros de Artistas Plásticos. Foundation For Today's Art/Nexus. Filadelfia 1995.

Vila Matas Enrique: Historia Abreviada de la literatura Portátil, Anagrama, Barcelona, 1996.

Walter Benjamín: Escritos, La literatura infantil, los niños y los jóvenes, De. Nueva Visión, Buenos Aires, 1989. 